\title{
BEP \& MAPPING PROCESS FOR THE RESTORATION BUILDING SITE
}

\author{
M. Lucarelli ${ }^{1}$, E. Laurini ${ }^{1}$, M. Rotilio ${ }^{1 *}$, P. De Berardinis ${ }^{1}$ \\ ${ }^{1}$ DICEAA, Civil, Construction-Architectural and Environmental Engineering Department, 67100 L'Aquila, Italy - \\ elelaurini@yahoo.it,marianna.rotilio@univaq.it, lucarelli_matteo@virgilio.it, pierluigi.deberardinis@univaq.it
}

\author{
Commission VI, WG VI/4
}

KEY WORDS: Hbim, Bep, Mapping Process, Rehabilitation, Building sites organization

\begin{abstract}
:
The BEP, acronym for BIM Execution Plan, consists of the information management plan created by the design team to illustrate how to meet the requirements defined in the Employer's Information Requirement (EIR).

The big amount of data will have to be organized a priori both for the professionals who will use that piece of information and for the stakeholders who will have to receive only the right information and use specific worksets. Just at this stage, the heart of the BIM method, there are different advantages compared to the traditional process, in which these informational steps were omitted, causing errors, delays and therefore an increase in active and passive costs. This paper explores the methodology applied to the mapping process of the management of a recovery site. For a better understanding of the result achieved, the stages of the process have been explained, from the acquisition of data, through the scan to BIM process up to the construction phases. In addition, the phases (Identify BIM goal and uses, Design BIM Project Execution Process, Develop information exchange) and the steps (Investigation, Identification and Strategy) necessary to achieve the objective have been analyzed. This is the Lean construction and Integrated Project Delivery (IPD), methodologies and systems that allow the improvement of the building process thanks to data sharing and communication between stakeholders before work begins so as to eliminate any possible delay.
\end{abstract}

\section{INTRODUCTION}

The contemporary society is undergoing a profound transformation due to the diffusion of new methodologies / work strategies and information technologies (ITC, Information Technologies in Construction) that are changing, even very quickly, the way of living, working, producing documents and exchanging information in order to get always updated and ready for use data. The BIMM meant as Building Information Modeling and Management is a necessary method, using the federated model, for data control and information management, throughout the building life-cycle or in order to optimize the processes of execution on site and maintenance after the closure of the works (Eastman et al., 2008).

The construction site is the place where the entire design process of the work materializes itself. Its tradition is linked to a clear, sometimes excessive, difference between what has been planned and what is being implemented. In particular it requires greater attention due to the unpredictability of the information and / or data that can arise not only during the design and interference identification phase (3D) but also in the management of construction site times and costs. For this reason the design and execution phase will be continuous and constant over time and must be managed by one specific professional figure who has all-round skills for the entire process.

It is precisely with the advent of digitization that a "new" idea of the construction site, the off Site, has emerged. Unlike the On site one, typical of the traditional process, it offers the opportunity to make many decisions and study different scenarios from the model. This allows to face the problems before they happen on site, guaranteeing time optimization. The On construction site, typical of the traditional process, is totally the opposite, where the variant and interference are common practice and even the executive project is designed and drafted in parallel with the execution (Jeong et al., 2016). This system, the Fast - Track, deceives the designer (Salvadori, 2000).

$\mathrm{He}$ thinks he is saving time and money but he is only introducing latent errors in the work that will cause only damage and inconvenience to the user and / or company. The traditional process is based on a series of work processes that do not interact with each other and follow each other without any principle of interoperability (De Berardinis et al., 2018).

This modus operandi involves various problems that affect the entire construction supply chain. Several complications arise within the team, where professionals do not interact with each other and when there is a lack of workflow of both activities and staff. This involves also a massive effort of time and energy to achieve mediocre results that must be changed regularly by the various stakeholders. In the perspective of an organization and evolution of the process, the drafting and sharing of the BEP, BIM Execution Plan (Yu-Cheng et al., 2016) are essential passages. This must be thought on the basis of information coming from the Employer's Information Requirement (EIR), in order to obtain the Customer's specific requirements (Figure 1). In the case study, presented below, the EIR has been organized according to three main aspects:

1. technical: specific software and features were necessary to make this process on the existing built context the most interoperable possible. At this stage, there was a great difficulty in having the right data operating in BIM according to certain standards, since the application of the method was still in an embryonic state. Another difficulty was the lack of relevant technical knowledge of the

\footnotetext{
* Corresponding author
} 
software and the transition from paper data to an integrated 3D model;

2. management: the work schedule was coordinated and the tolerances to use for the clash detection were identified because for the construction site establishment some areas required specific surveys and studies such as the case of vaults and their specific features or valuable elements;

3. commercial: the objectives of the client were specified, the deadlines to be respected with the relative drawings/ documents / and the format to be adopted.

The BIM Execution Plan arises from the need to communicate the flow of information, resources and project tools before each design phase. It also serves as a guarantor of the rules to ensure that all team members work following the established standards. It must meet certain requirements that can be included under the acronym S.M.A.R.T.: Specific, what is the stage / level to reach? Measurable, how to demonstrate the goal set? and to which actor in the process does it compete? Achievable, is it reachable? Realistic, is it realistically possible to get all the data according to the established methods? Time related, when will the goal be reached and who is monitoring the results? The main objective of the BIM Manager, author and controller of the BEP process, will be to define not only the single activities and / or steps to be followed but also the type and degree of responsibility of the stakeholders to ensure that the goal set is achieved (Ferrara et al., 2016).

\begin{tabular}{|c|c|c|}
\hline Technical & Management & Commercial \\
\hline $\begin{array}{l}\text { Software } \\
\text { platform } \\
\text { Data exchange } \\
\text { format } \\
\text { Co-ordinates } \\
\text { Level of detail } \\
\text { (general \& } \\
\text { components) } \\
\text { Training }\end{array}$ & $\begin{array}{l}\text { Standards } \\
\text { Stakeholders roles and } \\
\text { responsabilities } \\
\text { Planning the work and data } \\
\text { segregation } \\
\text { Security } \\
\text { Coordination and clash } \\
\text { detection process } \\
\text { Collaboration process } \\
\text { Model review meetings } \\
\text { Health and safety and } \\
\text { construction design } \\
\text { management } \\
\text { System performance } \\
\text { constraints } \\
\text { Compliance plan } \\
\text { Delivery strategy for asset } \\
\text { information }\end{array}$ & $\begin{array}{l}\text { Time of data drops } \\
\text { Clients strategic purpose } \\
\text { Defined BIM/project } \\
\text { deliverables } \\
\text { BIM specific competence } \\
\text { assesment }\end{array}$ \\
\hline
\end{tabular}

Figure 1. The table sets out the typical contents of an EIR

\section{RELATED WORKS}

The implementation of BIM is becoming increasingly widespread but some steps of this methodology are still unknown, especially as regards the Heritage BIM (Di Luggo et al., 2017). This is a much more complex procedure than the common BIM method, consisting of initial steps that require time and care in research.

To confirm this, existing buildings, regardless of their function, are detected using accurate instruments such as terrestrial laser scanners or point clouds.

Even if these tools detect a very exhaustive picture on the state of places, they cannot define automatically the characteristics of building components and their role is limited to documenting only what is captured on the surface. So in this case the immediate 3D model is missing and it must be created and subsequently consulted (Adan et al., 2011). Another difficulty for the HBIM method consists in the lack of downloadable and editable object products from the manufacturers' catalogs. In the specific model, a demanding implementation of a copious library of objects is required, that is generally not repeatable and therefore needs to be created from scratch in every single recovery project.

The BIM authoring environments, those that allow to work with smart objects able to relate to each other, require a high level of specialization on the part of the user, thus involving a designer approach rather than a mere user one.

This underlines the lack of existence of a BIM Modeler and the necessary presence of professional figures able to be designers and managers since the modeling phase (Rizzarda et al., 2017). A first and famous case of application of this methodology involved an interdisciplinary group called to work together towards a common goal: the need for safety of the structures and the need to preserve the architectural value of the Basilica of Collemaggio in L'Aquila (Brumana et al ., 2018). In particular, the first step was the creation in a parametric model based on a NURBS point cloud (GOG9-10) in order to obtain "SMART BIM" models to describe complex geometry and to match related information. The survey was carried out taking into account the final objective that is a model capable of reproducing geometric irregularities as much as possible.

A specific level of information (LOI) was therefore introduced to support the data retention process and create a detailed HBIM model in order to manage the analysis phases, simulation of the structural behavior, economic evaluation of the project and final restoration. Superficialities in not performing a rigorous and reliable model to reality are obviously found on the construction site, a place where the design materializes itself. The current problem, therefore, is to identify and develop a method based on an integrated 3D model that allows to obtain the following conditions: a work schedule more congruent with the reality of the site; an improvement in the process of identifying risk situations; an increase in the coordination and optimization of the use of resources; an optimization of communication with suppliers; a real time update of all modifications made during the implementation of the works and check of the related consequences on the management of the building site.

To obtain these characteristics, the research methodology to be applied on the construction site must follow several steps: definition of the elements to be contained in a CoSIM; definition of the graphic detail level of the model and its elements; definition of the development level of ergo-technical information; verification of the model with actual reality.

These characteristics can be found in contexts where one works purely in BIM, as in the case of the construction site located in the historic center of Milan and another one located in the historic earthquake-stricken center of L'Aquila. Both are the result of experimental theses carried out in the universities of the respective cities. They concern recovery sites and illustrate different aspects and difficulties that must not be underestimated or that must be solved directly on site. In the first one, the work group found great convenience in using the CoSIM method in relation to the cost - time of the project (Trani et al., 2015)

Sharing and viewing information and situations of the construction site with other designers since the initial design phase, has allowed for a significant reduction in time wasted in modification a number of times the pre-planning of the ergotechnique, thus obtaining a better design for health and safety. Therefore, the research methodology for the translation of ergotechnical contents into a BIM followed these steps: definition of the elements to be contained in a CoSIM; definition of the 
graphic detail level of the model and its elements; definition of the level of development of ergo-technical information; introduction of data in the federated model. In the case-study of the city of L'Aquila, in order to have full knowledge of the spaces and their use, all the work activities were graphed and the BIM federated model was consulted to increase risk management as much as possible and optimize the quality control of the work processes (Lucarelli et al., 2019).

Thanks to a 3D BIM model, advanced layouts were identified that report not only the change in the conformation of the site, but that are also closely related to a time schedule (4D management) so to easily check the work progress in relation to work schedule: we are on a certain day, we look at the model and then at the actual situation reality and draw the appropriate conclusions. Therefore checkpoints will also be needed to check the quality of the work performed.

\section{METHODOLOGY AND TOOLS}

The method adopted for this case study and also for the design of the BEP contains all the provisions concerning the BIM requirements that the project must have from the design phase up to the implementation phase (Ciribini et al., 2018). Unlike the common BIM method, concerning new constructions, the recovery method requires a quantity and quality of information that sometimes is not available or predictable (Garagnani, 2015). So if in the HBIM there is a continuous exchange of data between the phase of the detailed concept / design and construction, logically, this exchange will also occur in the BEP. It is important to reiterate that any discovery or action that is undertaken must be included in this initial phase of the process and shared with stakeholders. In this case study, the BEP is characterized by three main phases:

1. Phase 1: Identifying BIM goal e uses. This phase was useful to understand the know-how needed to achieve the objectives. Targets and priorities were established and specifically the tools and methods to use. This activity involved a reduction in the design phase duration, greater clarity of work processes among all stakeholders and the creation of a database of the existing building, essential for the facility management step. In creating the priority scale, the maximum value was attributed to two items: speed in the evaluation of the variant and precision in the immediate estimate of quantity and costs. Moreover some milestones were identified to revise the process evolution, already in this phase, with both appointed professionals and client;

2. Phase 2: Design BIM Project Execution Process. Once the BIM fields of application were identified, it was necessary to refer a general mapping of the process so that stakeholders could know all the process phases, the information to put in the shared models and the data to exchange. Already in this phase it is useful to establish a sequence and link of dependence between the parties so that every team manager can involve the right number of professionals with the more suitable skills.

3. Phase 3: Develop information exchange. At this point it was essential to define the information exchange process among all the project actors, fully respecting one of the key principles of BIM that is interoperability. Practically this operation translates into lists that define the inputs to be received, the outputs to be extracted and / or delivered, the LOD and LOA level, files (ifc \& cobie) and version to be used, maximum file size, unit of measure, tolerances, deadlines and related notes additions (Lerones et al., 2010). The general workflow indicates the set of parts and sequence between the various activities that make up the process, but it also contains the detailed mapping of each single processes. The mapping process concerning the management of the construction site, which required particular skills and competences of the BIM actors, will be discussed in more detail below. The procedure consists of three stages:

1. Stage 1: Survey. Working on Heritage BIM, an initial phase of diagnosis was essential to understand the way, the measure and the time needed to collect the right information and create an integrated architectural model of all the existing features.

The main objective was to reach a high LOA (De Vita et al., 2018). The objective of this stage is the achievement of a model of the current situation (As Is Model). In this regard, on the basis of the available tools, the different methodologies to be used for a fast and reliable survey were studied. This was implemented through the Scan to BIM process. Before the scan operation, performed with a Trumble TX8 scanner, some parameters were decided and also the degree of precision. Having to carry out a survey of an existing historic building for an end shipbuilding, the scan was very accurate and allowed to have immediately complete and accurate small size digital data, without having to go back to the site The data were subsequently inserted into the Trumble real works software which allowed both to calibrate the data and analyze the realistic model. Once this phase was completed, the model was inserted into Autodesk Revit for the management of work phases and activities like rendering, accounting and graphing related to the site safety (Figure 2).

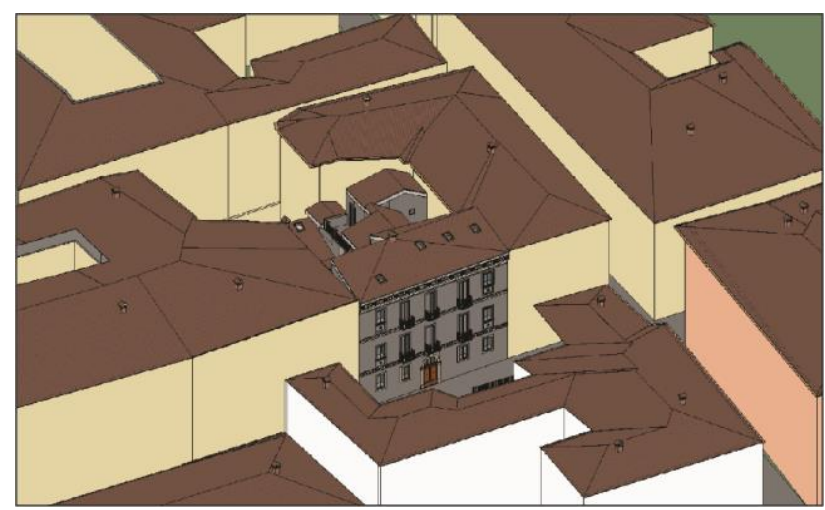

Figure 2. This picture show the model called As Is, got through scan to BIM process

2. Stage 2: Identification. The objectives and the Know How of HBIM application were defined, specifically the CDE (Common Data Enviroment) was created in this stage, The "As Is" model deriving from the survey phase and also from some surveys of the walls was inserted in the data sharing environment. This allowed the creation of a first basic model with all the available information such as material, energy and structural characteristics of the walls. In some parts, as it is was not possible to use the scanner, the traditional survey was used and, after designing it in $\mathrm{dwg}$. format and reproducing it in rvt. format, it was finally inserted into the general model. Being a pilot project, in addition to the LOA, a higher LOD than the classic LOD 300 was used as there was a millimeter detailed model and continuously updated. The CDE contains not only the 
"official" information such as reports or surveys carried out (also) in situ, but also the data relating to the context or special measures to take and all the shared models that can be used for the building management.

3. Stage 3: Strategy. It consisted in the identification of the mapping process of each phase. First of all, the following actions were fundamental: breaking down in a hierarchical manner the activities, roles and responsibilities of the phase; defining a link of dependence among the various activities since everyone must be aware of what happens before and after their intervention; identifying the verification activities of the process, necessary for the success of the BIM project as they allowed the project team to pause to make decisions and to check that the deliverables and the results of the project were fulfilled (Figure 3).

In addition to a series of activity checks, it is necessary to classify and direct the professionals, who will be responsible for their own activities and in cooperation with the professionals of the subsequent phase will have to set some checkpoints, in order to control the product qualitatively and quantitatively.

In case of a negative outcome, the activity must be restarted and the problems resolved as quickly as possible. This is important for a perfect distinction of the roles. In the case study analyzed, R.A.C.I. and R.A.M. matrices were created both in the design phase and in the execution phase. This way of working allowed the identification of roles and responsibilities of the activities, so as to avoid confusion and misunderstanding and to support the project manager.

Unfortunately, in recovery sites, these organizational procedures are necessary but not sufficient (Lucarelli et al., 2018).

In the case of a variant, it may distort the entire work devised at the beginning and therefore the BIM Manager will have to take care of the reorganization of the process in order to have no kind of delay and logically obtain a high quality product. Just for this reason, it is necessary to manage the worksets. They are collections of model objects, specific categories of objects, walls, floors, windows etc. useful in case of complex and articulated projects like this one. The use of worksets is fundamental for the complexity of some types of processing that require a specific process in order to eliminate any kind of interference. The worksharing methodology is useful not only to better manage the product and in a fast way but also to share the sense of work with colleagues as well as the ability to relate to others (Figure 4).

\section{CONCLUSIONS}

The management of the building process in the execution phase involves numerous planning activities and checks. For this purpose, having a 3D digital representation available through the Scan to BIM process is indispensable and offers a double benefit. At the beginning, as it has been explained, there is an "As Is model", regarding the current situation while both during the work process and after the building site closure, a model called "As Worked" can be obtained. This model provides a real feedback on the work performed and allows to quickly verify if the detected model is superimposable to the designed one.

This guarantees a control of the whole process, a clear reduction of errors on site and also time and cost optimization.

With the process digitization and the detailed process programming, the traditional methodology represented by the Gantt and Pert has been integrated with new systems such as the "Lean Construction".

In the organization of the above mentioned site, the CPM outlined the expiry of the project (milestone) and the sequence of critical activities while the Lean methodology has allowed to plan in detail the work in the time frame of four / five weeks.

Mapping Process building site management

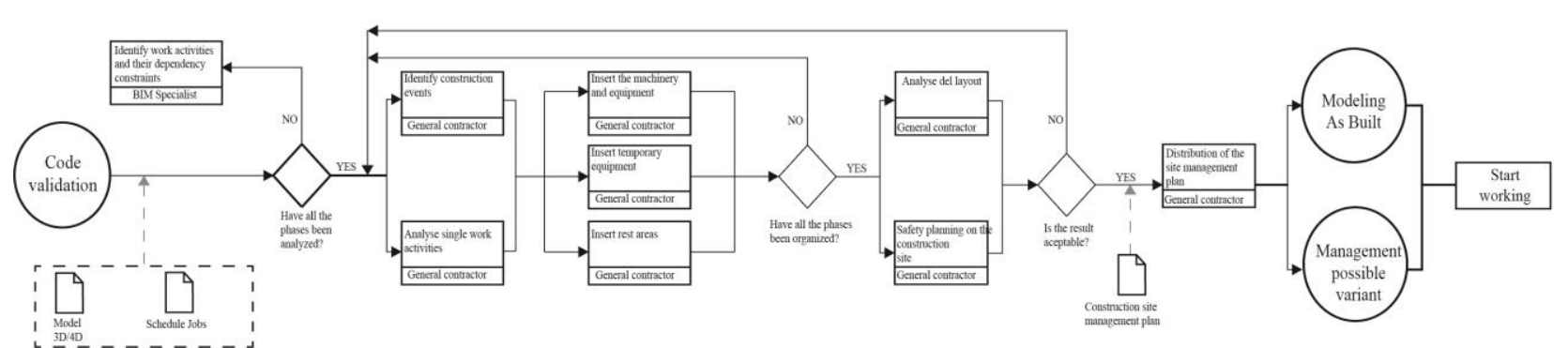

Legend Mapping Process
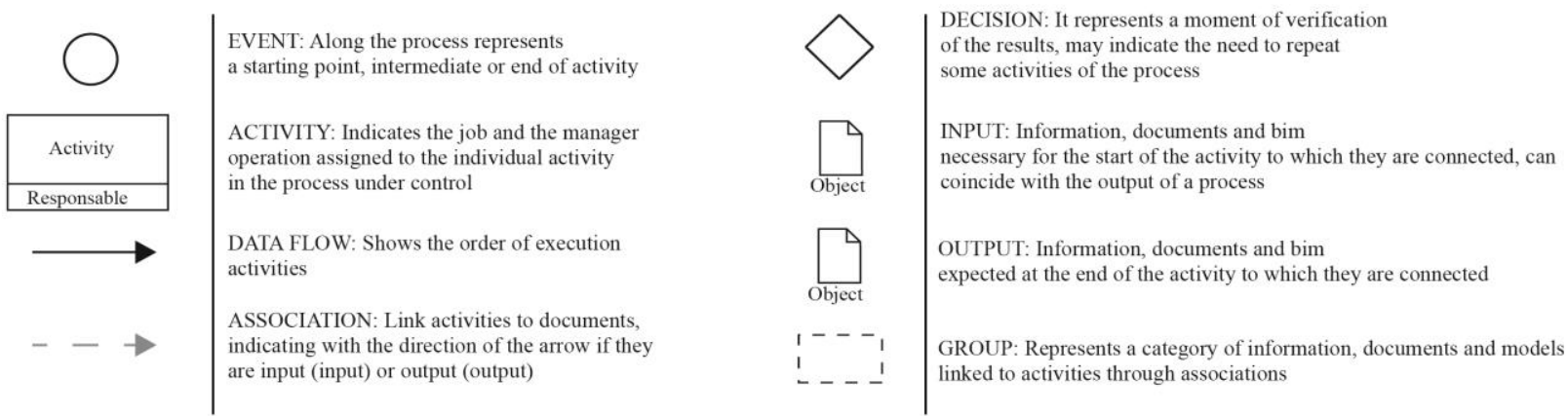

Figure 3: Example of mapping process used in HBIM 


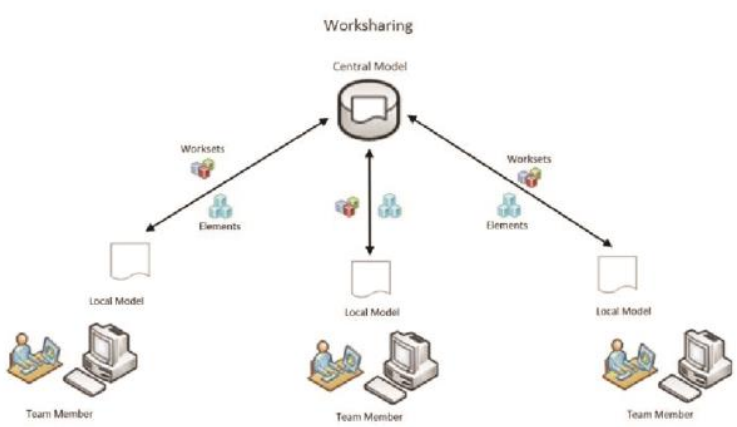

Figure 4. Worksharing. Team members share a central model

The study and application of the BEP improves communication within a project team, simulating a highest level of design and construction of projects.

All this materializes in the IPD, Integrated Project delivery, a collaborative fusion of people, tools, systems that operate with the same precise objective (Figure 5).

This leads to a shared environment of information, always updated, so to have increasingly advantageous solutions more easily and without any delay. Furthermore, the application of this methodology allows obtaining an interactive database on the history of each building that will guarantee a solid foundation for possible and / or future operations.

In conclusion, the innovative approach of this case study is that it is goes beyond the classic and limiting stereotypes of the recovery site or the attitude "we have always done this way": the described process has reached the prefixed objectives through professional figures, innovative tools and software, ensuring a replicable methodology in different contexts.

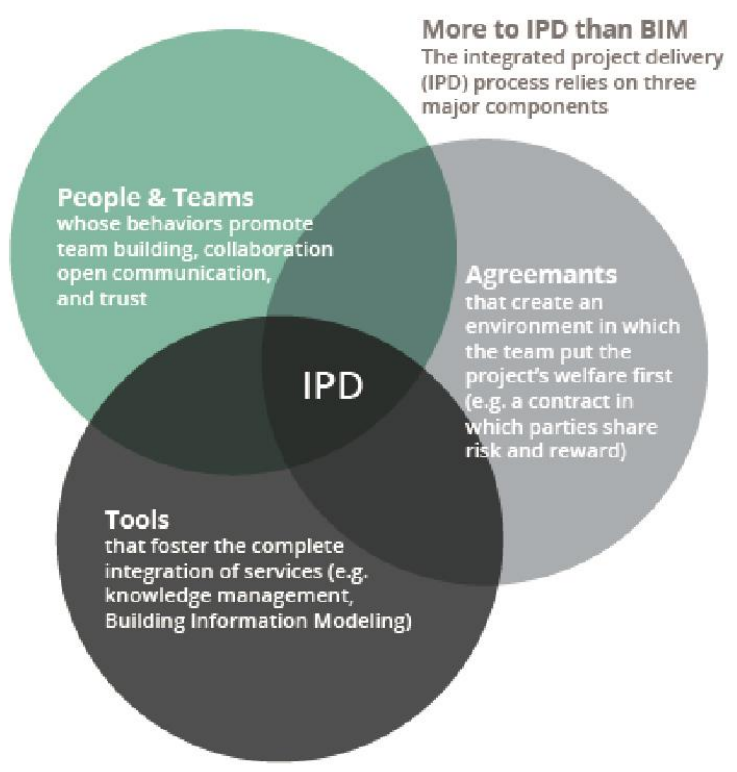

Figure 5. IPD Scheme. The integrated project delivery process relies on three major components: people \& teams, agreements, tools

\section{ACKNOWLEDGEMENTS}

M.L. defined the structure and organization of the article. M.L. wrote the article. E.L. and M.R. supervised, integrated and corrected the paper.

The research group consisted of all the authors. In particular P.D. was responsible for the scientific research.

The study presented in the article was developed within the research group "Production of the building industry and rational management of the construction process on site", DICEAA, University of Study of L'Aquila.

\section{REFERENCES}

Adan A., Xiong X., Akinci B., Huber D., 2011. Automatic creation of semantically rich 3D building models from laser scanner data. In Proceedings of the 28th International Symposium on Automation and Robotics in Construction (ISARC), pages 342-347, Seoul, Korea.

Brumana R., Della Torre S., Previtali M., Barazzetti L., Cantini L., Oreni D., Banfi F., 2018. Generative HBIM modelling to embody complexity (LOD, LOG, LOA, LOI): surveying, preservation, site intervention - the Basilica di Collemaggio (L'Aquila). Applied Geomatics, Volume 10, Issue 4, pp 545567.

Ciribini C. L. A., ITC CNR., 2018. Le Criticità del Piano di Gestione Informativa (BIM Execution Plan). Ingenio Magazine. ISSN 2307-8928.

De Berardinis, P., Di Giovanni,G., Laurini, E. Rotilio, M., 2018. Progettare l'organizzazione del cantiere di recupero nell'ambito della ricostruzione post sismica all'Aquila. In: $\underline{\text { Gth Convegno }}$ Internazionale ReUSO, Messina, 1489-1500.

De Vita M., Trizio I., Savini F., De Berardinis P.,2018. Cultural heritage and earthquakes: a multidisciplinary approach to restoration sites. Vitruvio International journal of Architecture Technology and Sustainability Volume 3 issue 2.

Di Luggo A., Pulcrano M., Scandurra S., Tarantino C., 2017. In 3D Modeling \& Bim, progettazione, design, proposte per la ricostruzione. H-BIM modeling and historical reconstruction of of architectural heritage. pp. 178-195. Tipografia del Genio Civile.

Eastman C., Teicholz P., Sacks R., Liston K., 2008. BIM Handbook: a guide to building information modeling for owners, managers, disegners, engineers and construction; J. Wiley \& Sons: Hoboken. New York.

Ferrara, A. Feligioni, E., 2016. BIM e Project Management, Dario Flaccovio Editore, pp. 16-25.

Garagnani S., 2015. HBIM nell'esistente storico Potenzialità e limiti degli strumenti integrati nel recupero edilizio. Ingenio Magazine, pp. 3 - 5. ISSN 2307-8928.

Jeong W., Chang S., Son J., Yi J., 2016. BIM-Integrated Construction Operation Simulation for Just-In-Time Production Management. Sustainability Journal Volume 8 Issue 11.

Lerones P., Fernandez L., Gil M., Gomez - Garcia - Bermejo J., Casanova E., 2010. A pratical approach to making accurate 3D layouts of interesting cultural heritage sites through digital 
models. Journal of cultural heritage 11. Elsevier, pp. 1 - 9.

Lucarelli M., Laurini E., Rotilio M., De Berardinis P., 2018. Metodo BIM: gestione dei cantieri edilizi nei centri colpiti da calamità naturali. Convegno Reuso 2018. Vol.1, pagg 2531 2542. Roma - Gangemi Editore, ISBN: 978-88-492-3659-0, Messina, 11- 13.

Lucarelli M., Laurini E., De Berardinis P., 2019. 3D and 4D Modeling in building site working control. In 8th International Workshop 3D-ARCH 3D Virtual Reconstruction and Visualization of Complex Architectures. ISPRS Volume XLII2/W9.

Rizzarda C., Gallo G., 2017. La sfida del BIM. Un percorso di adozione per progettisti e imprese. Tecniche nuove, pp. 64-80. Salvadori M., 2000. Perchè gli edifici stanno in piedi?

Strumenti

Bompiani, pp. 117 - 127.

Trani L. M., Cassano M., Todaro D., Bossi B., 2015. BIM Level of Detail for Construction Site Design. Procedia Engineering 123:581-589.

Yu-Cheng L., Yen-Pei C., Wan-Ting H., Chia-Chun H., 2016. Development of BIM Execution Plan for BIM Model Management during the Pre-Operation Phase: A Case Study. Buildings Volume 6 Issue 1. 